\title{
Mononuclear phagocytes in head and neck squamous cell carcinoma
}

\author{
Kenneth Wilfried Kross · John-Helge Heimdal • \\ Hans Jørgen Aarstad
}

Received: 23 June 2009 / Accepted: 30 October 2009 / Published online: 5 December 2009

(C) The Author(s) 2009. This article is published with open access at Springerlink.com

\begin{abstract}
The head and neck squamous cell carcinoma microenvironments contain many immune cells and their secretory products. Many of these cells belong to the mononuclear phagocyte system. The aim of this review is to study the interactions between mononuclear phagocytes and head and neck squamous cell carcinoma tissue. The role of inflammation in tumours and the cytokine interleukin-6 will be highlighted. Future therapy strategies in the treatment of head and neck cancer might be directed towards mononuclear phagocytes and their cytokine production.
\end{abstract}

Keywords Mononuclear phagocytes $\cdot$ Innate immune system · Macrophages $\cdot$ Monocytes $\cdot$ Interleukin- 6 . Fragment spheroids $\cdot$ Head and neck squamous cell carcinoma

$\begin{array}{ll}\text { Abbreviations } \\ \text { VEGF } & \text { Vascular endothelial growth factor } \\ \text { TGF- } \beta & \text { Transforming growth factor } \\ \text { GM-CSF } & \begin{array}{l}\text { Granulocyte-macrophage colony stimulating } \\ \text { factor }\end{array} \\ \text { TRAIL } & \begin{array}{l}\text { Tumour necrosis factor-related apoptosis induc- } \\ \text { ing ligand }\end{array}\end{array}$

K. W. Kross $(\square)$

Department of Otolaryngology, Head and Neck Surgery, Maastricht University Medical Centre, PP Box 5800, 6202 AZ Maastricht, The Netherlands

e-mail: kenneth.kross@mumc.nl

J.-H. Heimdal · H. J. Aarstad

Department of Otolaryngology, Head and Neck Surgery,

Haukeland University Hospital Bergen, Bergen, Norway $\begin{array}{ll}\text { EGF } & \text { Epidermal growth factor } \\ \text { PGE2 } & \text { Prostaglandine E2 }\end{array}$

\section{Introduction}

Head and neck cancer (HNC) is a heterogeneous group of diseases involving the oral cavity, pharyngeal tube and larynx. In the United States, where the population is approximately 300 million, an estimated 40,500 new cases of HNC arose in 2006, with an estimated mortality of 11.170 persons [1]. Worldwide, 644,000 new cases of HNCs are estimated to be diagnosed each year, with almost twothirds occurring in developing countries [2]. In some of these countries, HNC can be one of the most common malignancies. This is mostly due to factors such as poor oral hygiene, chewing of betel nuts, smoking and drinking of alcohol [3], but other factors such as genetic susceptibility and virus infections may play a role in the carcinogenesis of HNC [4]. Over $90 \%$ of malignancies in the upper aero-digestive tract are squamous cell carcinomas (HNSCC) [5].

HNSCC is usually treated with surgery and radiotherapy either combined or one modality alone. In the past years, advances in surgical treatment have been mainly made on the field of organ preservation and more effective means of reconstruction [6]. Recent advances in radiotherapy include altered fractionation radiotherapy and radiotherapy combined with chemotherapy for patients with locally advanced tumours $[7,8]$. However, this combined treatment might be associated with severe side effects [9]. Many advances in diagnosis and treatment have been made but the survival rate for HNSCCC remained stable for the last decade and is rather low [5]. The highest 5-year survival is for lip cancer, at $91 \%$ but just $31 \%$ for hypopharyngeal cancer [5]. There 
is, therefore, a demand for new therapies to improve the survival of HNSCC patients.

\section{Challenges in treatment of HNSCC}

Many advances have been made in understanding the carcinogenesis and biology of cancer and metastasis. Several new areas of research have emerged involving biologic compounds targeting specific regions in the cancer cell. One area of special investigation is the epithelial growth factor receptor (EGFR) which is expressed in more than 90\% of HNSCC tumours and is associated with a poor prognosis [10]. EGFR inhibitors hold promise in two important ways: [1] to further improve efficacy for patients at risk for recurrence and [2] to decrease treatment-related toxicities by replacing toxic cytotoxic drugs without jeopardizing survival [11]. Several clinical studies have been performed where monoclonal antibodies, directed against the extracellular domain of EGFR, are administered, or several small molecule tyrosine kinase inhibitors are given [12] These substances are administered combined with radiotherapy or chemotherapy [13]. Results are promising despite severe side effects, but a new standard of treatment is yet to be found in the clinic [13].

The innate immune system may interact with cancer cells, both as an inhibitor [14] and facilitator [15] of tumour growth. This interaction allows using immunomodulating therapies of cancer by more or less generalized stimulation of mononuclear phagocytes (MNP). Killed bacterial toxins [16], along with bacillus Calmette-Guerin (BCG) [17], $\beta$ glucan [18], interferons [19] and monoclonal antibodies [20] are examples of applied biological response modifiers (BRMs), used as immune stimulators in tumour treatment.

In Japan, it has been a long-standing tradition to use penicillin-killed lyophilized Streptococcus pyogenes, denominated OK-432 or picibanil, as a BRM in cancer treatment [21]. Sakamoto et al. [21] published in 2001, a meta-analysis where the benefits of immunochemotherapy with OK432 were assessed in patients with resected non-small-cell lung cancer. The meta-analysis was based on data from 1,520 patients enrolled in 11 randomized clinical phase III trials. The 5-year survival rate for all eligible patients in the 11 trials was better with OK-432 treatment, i.e. $51.2 \%$ in the immunochemotherapy group versus $43.7 \%$ in the chemotherapy group. Furthermore, Oba et al. [22] have shown that patients with resectable gastric carcinoma treated with adjuvant immunochemotherapy, with OK-432 as one component, may improve their survival (performed was a metaanalysis on 8,009 patients from eight randomized clinical phase III trials). There are also reports suggesting that patients with other cancers, such as HNSCC [23], may benefit from OK-432 treatment. OK-432 may also be used as a maturation factor for dendritic cells (DCs) as part of vacci- nation therapy of cancer patients [24]. Despite these convincing results for OK-432 as cancer treatment, OK-432 treatment has not gained any important role as a cancer drug in Europe or USA. Other new therapies might be directed towards other target receptors on the cancer cell such as the Fas receptor [25]. This, as well as other new (gene) therapies, has not been properly developed, nor have there been, to our knowledge, performed any clinical studies.

\section{Cancer and the human immune system}

The degree of interaction between tumours and the immune system has been discussed for more than a century. Theories have been proposed with respect to general tumour immunology, as well as strategies for immunotherapy in the treatment of malignant diseases. Ehrlich observed, in 1909, in animal experiments that recipient mice could acquire immunity to tumour growth. He suggested that the immune system could detect and respond to cancer cells because the cancer cell was considered a foreign element by the organism. Later, this view was further substantiated and systematized to become the theory we now know as the "immune surveillance" theory [26]. This theory hypothesizes that malignant cells are exposed to tumour-associated antigen determinants on their cell surface. These antigens then induce a $\mathrm{T}$ lymphocyte-dependent immune response that eventually eliminates tumour cells [26]. According to the theory of immune surveillance, a malignant tumour may only arise when malignant cells escape an immune response [27]. There is experimental evidence that malignant tumours can elicit a specific $\mathrm{T}$ cell-mediated immune response and suppression of the immune system increases the incidence of certain types of cancers in humans [28]. Scepticism has been stated towards the general relevance of immune surveillance in humans [29] and any firm role of immune surveillance in HNSCC patients has yet to be established [28]. Still, observations from several studies indicate that immune system-related mechanisms may act either as stimulatory or inhibitory regulators on the development and spread of malignant diseases in humans [30]. Active immune mechanisms protecting the organism against distant spread of cancer are demonstrated in animal models [31, 32] and may argue that immune system-related mechanisms act against tumour cell spread, also in humans. These immune mechanisms apparently fail to eliminate tumour cells in progressive cancer disease. This incapability of the immune system may be attributed to three principally distinct reasons [33]:

A. Escape by loss of recognition (loss or alteration of molecules which are important for the recognition by and activation of the immune system) 
B. Escape by loss of susceptibility (escape from effector mechanisms of cytotoxic lymphocytes)

C. Induction of immune cell dysfunction

When developing effective strategies for the treatment of HNSCC, a thorough understanding of tumour cell escape mechanisms becomes fundamental. Cells of the immune system may not only fail to act against tumour growth, but, according to several reports may also support tumour cell growth. This is, e.g. the case for MNP cells that secrete growth factors and factors contributing to neoangiogenesis by stimulating proliferation and migration of endothelial cells and local degradation of the extracellular matrix (ECM) [34]. Immune cells should therefore be regarded as possible "friends or foes" when one discusses interactions between tumours and the immune system.

Inflammation, cancer and the human immune system

A relationship between cancer and inflammation has since long been discussed and epidemiological and experimental evidence points to a connection between chronic inflammation and development of dysplasia followed by development into cancer [35]. Inflammation is a very complex process where many effector cells and mediators are involved potentially facilitating tumour growth through multiple mechanisms [36].

Inflammation in tumours

Solid cancers generally show signs of inflammation with influx of many types of leukocyte populations. In a deficient immunosurveillance situation, a switch may occur where cells of the MNP (mainly TAMs) change their phenotype from pro-inflammatory to pro-angiogenic, contributing to tumour progression via secretion of proteases, cytokines and angiogenic factors [34]. Chronic inflammation can be caused by viruses and contribute to cellular transformation [37] while bacterial infection may play a role when an organisms produces free radicals, such as reactive oxygen and/or nitrogen species, causing DNA damage and mutations leading to tumour development. Chronic inflammation, furthermore, elevates a population of myeloid-derived immunosuppressive cells that inhibit anti-tumour immunity [38]. IL-1 $\beta$ is a cytokine that plays a role in this process. In a recent study, mice deficient for IL-1 receptor (IL-1R) were inoculated with mammary cancer cells and compared to non-deficient mice. Tumour-associated inflammation as well as tumour progression was delayed in IL-1R-deficient mice as well as number of suppressive myeloid cells. Tumour progression as well as progression and number of suppressive cells could be restored by administering IL- 6 , a pleiotropic cytokine known as a mediator of IL- $1 \beta$, and from that perspective, a contributing factor in tumourigenesis [36]. For colitis-associated cancer, an animal model has been developed that reproducibly leads to colonic neoplasia within the setting of colitis. In this model, a carcinogen is administered followed by three rounds of chemical colitis induced by a chemo-irritant in drinking water. After 12 months of treatment, nearly $100 \%$ of mice developed neoplasms in the colon. This model has shown that mucosal-derived Nuclear Factor-(NF-) $\kappa \mathrm{B}$ factor is activated. $\mathrm{NF}-\kappa \mathrm{B}$ is a pleiotropic transcription factor which plays a role in both innate and adaptive immunities, and is required for the expression of several pro-inflammatory factors $[39,40]$. Seen from this perspective, (chronic) inflammation might be a key factor in cancer development. As the head and neck area is prone to exposure to factors causing irritation and inflammation of the squamous epithelium, it might therefore be plausible that chronic inflammation also might be a major cause for the development of HNSCC. It has been shown that NF- $\kappa$ B and its proinflammatory target genes are activated in HNSCC cell lines and tumour specimens [41]. Blocking $\mathrm{NF}-\kappa \mathrm{B}$ function in HNSCC greatly reduces tumour growth and decreases the expression of IL- 6 and IL- 8 along with many other cytokines and chemokines associated with the proinflammatory state [42]. As the constitutive activation of $\mathrm{NF}-\kappa \mathrm{B}$ is well established, the mechanisms of this activation in HNSCC still needs to be fully elucidated [41].

\section{Adaptive immunity and HNSCC}

In HNSCC, stroma is infiltrated with tumour-infiltrating lymphocytes (TIL).

T-lymphocyte-stimulated proliferation decreases with increasing tumour burden in HNSCC patients [43]. Tlymphocyte function, subpopulations in peripheral blood as well as growth factor responses, may be correlated to prognosis in HNSCC [44]. A recent publication showed that total percentage of CD4+ T-cells was significantly decreased in patients versus controls and that proportion of $T_{\text {reg }}$ cells was significantly elevated in patients relative to healthy donors. These cells seemed to downregulate subsets of CD8+ cells, which may play a role in antitumour responses [45]. In a recent study, Aarstad showed that that a high level of peripheral blood (PB)-derived Tlymphocyte activation in vivo can predict impaired prognosis with and without adjustment for TNM stage in HNSCC [46]. The amount of peripheral blood lymphocytes might be correlated to tumour load as expressed by node status. 


\section{HNSCC and monuclear phagocytes}

The HNSCC microenvironments also comprise immune cells and their secretory products. The presence of immune cells, mainly $\mathrm{T}$ lymphocytes and dendritic cells (DC) but also of B cells, plasma cells, natural killer (NK) cells, macrophages (M $(\mathrm{s})$ and eosinophils, as well as proximity to cervical lymph nodes, is likely to have an effect on the initiation, promotion and progression of HNSCC [47]. Cells of the MNP develop from myeloid progenitors in the bone marrow and are not only important for innate immunity but also play a central role in specific adapted immunity. In addition, MNPs participate in several biological processes, e.g. disposal of dying cells, ingestion of aged erythrocytes, regulation of inflammatory processes, e.g. tissue repair, initiating coagulation and stimulation of chemotaxis [48-50]. After maturation and subsequent activation MNPs achieve varied morphological forms. Monocytes (MOs) may, after 2-3 days in circulation at baseline conditions, move into different tissues and further differentiate into macrophages $(\mathrm{M} \varphi \mathrm{s})$. M $\varphi s$ associated with tumours are called tumourassociated macrophages (TAMs). MNPs, in general, may act as defence cells and phagocytes even in the absence of activation. MNPs are effective as Antigen presenting cells (APCs) and are involved in the regulation of immune responses via interaction with lymphocytes and as effector cells in adaptive immune response [51]. The functional capacity of MNPs depends on the activation level of the cells.

$\mathrm{M} \varphi s$ are relatively large, irregularly shaped cells measuring $25-50 \mu \mathrm{m}$ in diameter. The nucleus is round or kidney-shaped and often eccentrically placed with one or two nucleoli. Often there is a clearly defined juxtanuclear Golgi complex in an abundant cytoplasm [52]. Monocytes (MOs) are small cells measuring $12-15 \mu \mathrm{m}$ with an eccentrically placed nucleus which occupies at least $50 \%$ of the cell area. The cytoplasm contains both fine and large granules as well as cytoplasmic vacuoles [52].

Phenotypic and functional changes have been described in MOs from patients with different types of cancer, upon comparison to controls. In prostate cancer patients, peripheral blood has high levels of phenotypical immature MOs compared to healthy individuals [53]. Recent data have demonstrated that myeloid cells accumulating in cancer patients play an important role in tumour non-responsiveness via suppression of antigen-specific $\mathrm{T}$ cell responses [54]. On the other hand though, it has been shown that MOs from cancer patients are activated compared to healthy controls $[55,56]$, but contact with tumour cells can decrease function of MOs in cancer [57]. Although some of the results are conflicting, there is evidence suggesting that functional activities, as expressed by, e.g. cytokine secretion of MOs in cancer patients, are changed. Changes observed in systemic responses such as immune responses, acute phase inflammatory protein responses and decreases in delayed-type hypersensitivity in HNSCC patients are not well understood. Still, the local and systemic nature of these responses suggests that cytokines with pro-inflammatory, pro-angiogenic and immunoregulatory activity produced by carcinomas could contribute to the pathogenesis of HNSCC disease. Cytokines that regulate pro-inflammatory and pro-angiogenic responses are detected in tumour environment as well as systemically in HNSCC patients [58]. It might not be just tumour-derived factors which contribute to growth and metastasis of the tumour itself. Observations from several studies have linked certain subsets of the innate immune system to factors such as clinical prognosis, tumour angiogenesis and invasion [59-62], and it is now clear that certain subsets of chronically activated innate immune cells promote growth and/or facilitate survival of neoplastic cells [63]. In the tumour microenvironment, as well as in circulation, there are different immune cells that can produce cytokines having these effects. Among the cells with most active cytokine secretion are the MNPs.

\section{HNSCC-derived factors affecting MNPs}

Our laboratory developed an organ culture model whereby fragment spheroids were established from head and neck squamous cell carcinoma tissue and autologous benign squamous tissue. These fragment spheroids served as vectors for tumour cells in co-cultures with autologous monocytes. Fragment spheroids developed within 14 days of in vitro culture whenever adequate tissue was available. Experiments have shown that MCP-1 production by MOs as well as TAM density in HNSCC tissue was inversely correlated with Erythrocyte Sedimentation Rate level at diagnosis and co-culture [64]. In other words, presence of "general" inflammation suppresses MNP functions, as expressed by MCP-1 production. Thus, MNP function in HNSCC patients seems more to be related to the inflammatory state of the organism, than previously recognized. We could not define a statistically significant correlation between TNM stage and TAM density, but there was a trend showing a greater density of $\mathrm{M} \varphi s$ in Malignant F-spheroids from more advanced TNM staged tumours. Though not statistically significant, these results correspond to other reports correlating TAM density and function to prognosis in cancer patients [65] as well as a strong association between $\mathrm{M} \varphi$ content, $\mathrm{N}$ stage and lymph node metastasis in oral SCC tumours [66]. A thorough understanding of these mechanisms lends promise to future cancer therapy based on modulating interactions between tumour cells and the MNP system. 
Fig. 1 Possible functions of TAMs in tumour establishment and development. A high accumulation of TAMs in tumours can be associated with increased neo-angiogenesis but have also the potential to act cytotoxic against tumour cells by secreting different kinds of cytokines

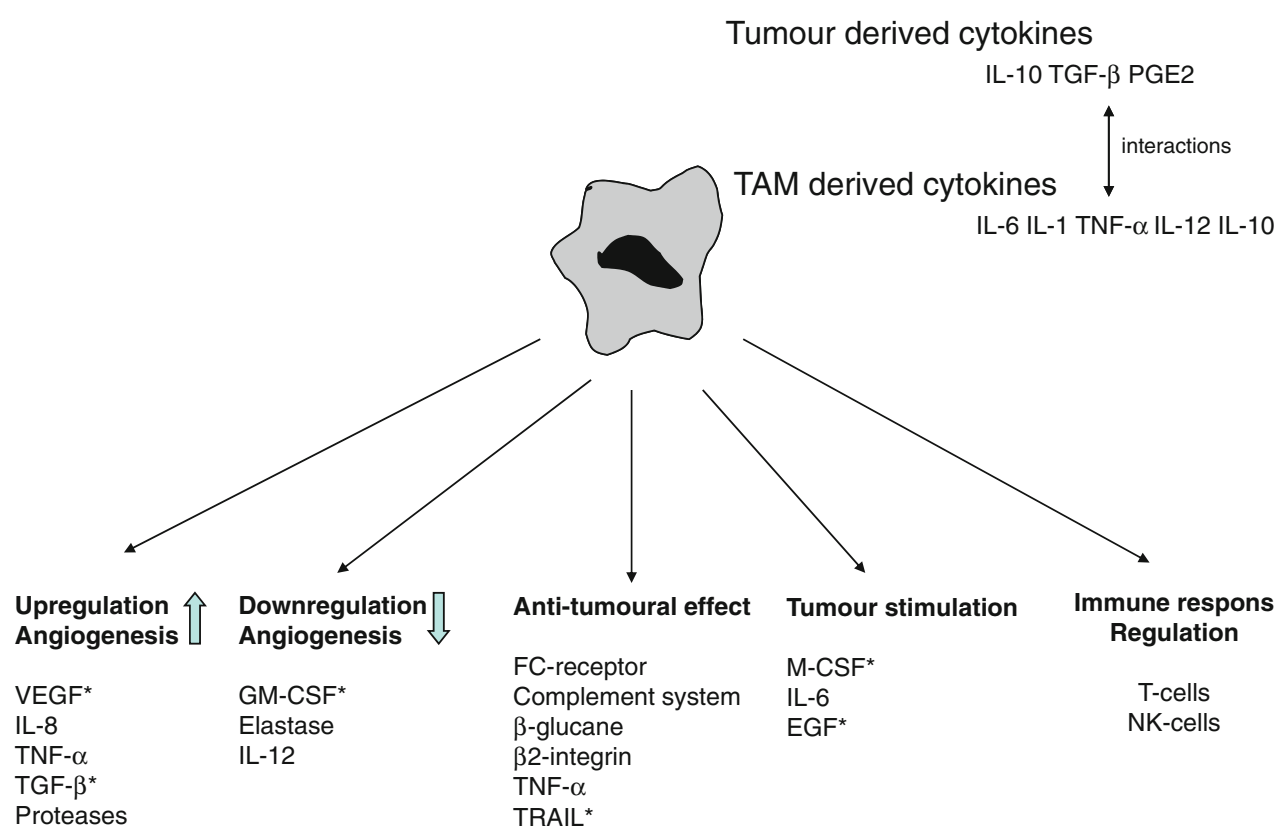

Tumour-associated macrophages

TAMs may play a dual role in the interaction with tumour cells [67] (Fig. 1). In some situations, a symbiotic relationship may exist between TAMs and tumour cells, thereby providing support to the tumour in terms of growth and metastasising capacity. It has, e.g. been shown that a high amount of TAMs in tumours can be associated with increased neo-angiogenesis and a worsened survival rate [68]. TAMs also have the potential for acting cytotoxic towards tumour cells and some reports state an improvement in prognosis associated with high numbers of TAMs in tumours [69]. Correlation analyses between number of TAMs and prognosis in HNSCC have, however, shown that high levels of TAMs in HNSCC may be related to worse long-term prognosis [61, 66]. This might be different in other cancer diseases [30, 68, 70-73]. In recent years, evidence has been provided on $\mathrm{M} \varphi s$ being induced by cytokines to polarize into two distinct groups. These two groups differ in receptor expression, cytokine and chemokine production as well as effector function [67, 74]. Type I M are effector cells which kill micro-organisms and tumour cells and produce anti-inflammatory cytokines while Type $2 \mathrm{M} \varphi$ s regulate inflammatory responses and adaptive Th immunity, act as scavenger cells, promote angiogenesis, tissue modelling and repair. This definition, however, does not take into account that M $\varphi$ s are not static and that functional and phenotypic changes occur during inflammatory responses, thereby inducing $\mathrm{M} \varphi \mathrm{s}$ into an evolving shift in functional activities and into an unstable, undefined and non-functional phenotype [75]. This plasticity of M $\varphi s$ was, e.g. demonstrated by Watkins et al. [59] in a mouse model. Functionally polarized TAMs could be converted, from a tumour-supportive and immunosuppressive phenotype to an inflammatory functional phenotype, by IL-12 treatment in vivo as well as in vitro.

\section{Cytokine production and MNPs}

Cells of the MNP system secrete many different mediators of the immune response, such as cytokines and chemokines. When MNPs are activated, genes expressing various inflammatory mediators are induced, some among these being cytokine genes. The genes encoding cytokines IL- $1 \beta$, IL-6, and TNF- $\alpha$ are closely regulated and classified as early or immediate genes. These cytokines are denominated pro-inflammatory [76]. MNPs also secrete peptides, such as monocyte chemoattractant protein-1 (MCP-1) that have chemoattractant effects. Many studies have been done on functions and clinical relevance of MCP-1, IL-6 and TNF$\alpha$. These are highlighted in this review.

Interleukin-6

Interleukin-6 (IL-6) is a $26-\mathrm{kDa}$ protein that is a potent, pleiotropic, inflammatory cytokine mediating many physiological functions, including developmental differentiation of lymphocytes, cell proliferation and cell survival, as well as apoptosis. Furthermore, IL-6 has an effect on bone formation, general system metabolism, endocrine functions and can affect many cells in other tissues and organ systems [77, 78].

The IL-6 receptor (IL-6R) is composed of a ligand-binding $\alpha$ subunit and a signal-transducing component, designated gp130. A high production of IL-6, by MOs in cancer patients with recurrence and/or death from disease, might 
be linked to an IL-6/gp130 autocrine/paracrine mechanism activating Signal Transducer and Activator of Transcription-(STAT-)3 in an EGFR-independent matter [79]. STAT3 activation is associated with cell proliferation and prevention of apoptosis, thereby participating in oncogenesis [80], and has been shown to be up-regulated in HNSCC tissue and in the normal mucosa of the same patient [81]. Recently, IL-6 was shown to have not only an augmenting influence on the invasion potential of HNSCC cell lines but also an inhibiting effect on proliferation rate $[82,83]$.

\section{Monocyte chemoattractant protein-1 (MCP-1)}

Chemokines, a family of low-molecular-weight cytokines that play key roles in immune response and in development of several cell types, are classified mainly into CC and CXC subfamilies according to location of the first two cysteine residues. MCP-1 (or CCL2) was originally thought to be a selective chemokine for MOs, but later been shown to also have effects on T lymphocytes [84], NK cells [85] and basophilic granulocytes $[86,87]$. MCP- 1 is structurally and genetically related to other chemokines (MCP-1, $-2,-3$, and -4 in humans, MCP-1, $-2,-3$, and -5 in the mouse) with similar properties. They all activate the same receptor, CCR2, with similar potencies [88]. Many studies have been performed relating synthesis of MCP-1 and influx of TAMs in tumour tissue and relating this influx to factors, such as angiogenesis, invasion and prognosis [61, 62, 70]. Lately, evidence has been provided on MCP-1 possibly being responsible for recruitment of myeloid suppressor cells into tumour. As such, having a pro-tumour effect in itself [89]. Various types of cancer cells, including ovarian, breast and colorectal cancer cells, synthesize and express chemokine receptors [90].

\section{Tumour Necrosis Factor- $\alpha$ (TNF- $\alpha)$}

Tumour Necrosis Factor-(TNF-) $\alpha$ is a polypeptide of 157 amino acids and in humans. It is expressed on the cell membrane of a majority of cells, with the exception of erythrocytes and resting T lymphocytes [91]. TNF- $\alpha$ is a pleiotropic cytokine and plays an important role in the pathophysiology of different diseases, such as sepsis and rheumatoid arthritis. Blocking TNF- $\alpha$ production is very effective in reducing local and systemic inflammation in patients with rheumatoid arthritis and psoriasis [92]. TNF- $\alpha$ promotes killing of tumour cells through apoptosis via binding with death-domains in tumour cells, stimulating NK cells and activating CD8+ cells [93].

TNF- $\alpha$ molecules are membrane-bound or circulate in two forms, either as biological active molecules or as immunologically detectable but inactive peptides. There are inhibitory mechanisms that protect cells from TNF- $\alpha$ activity, such as circulating TNF receptors and membranebound "decoy" receptors [93].

Transcripts of protooncogenes (c-jun and c-fos), transcription proteins, such as the immediate-early growthresponse transcription factor Egr-1 as well as subunits of $\mathrm{NF}-\kappa \mathrm{B}$ family $\mathrm{p} 50$ and $\mathrm{p} 65$, are involved in induction of TNF- $\alpha$ gene transcription by binding to specific sites on the $\mathrm{TNF}-\alpha$ promoter region [94].

Monocyte IL-6 production as a prognostic factor

Our research showed that IL-6 secretion by LPS-stimulated MOs from HNSCC patients predicted prognosis [95]. Furthermore, we found a correlation as to the amount of IL-6 produced in co-culture of MOs with F-spheroids and recurrence of disease, as well as prognosis of patients [96]. For MCP-1 though, we could not find any major correlation as to recurrence and prognosis. This general, predictive, value of IL-6 secretion from MOs stimulated with different stimuli, such as LPS and co-culture, is interesting as well as intriguing. In LPS-stimulated MO cultures the main source of IL-6 is the MO as low levels of IL-6 in serum minimally contribute to the total amount. In a recent longitudinal and prospective cohort study Duffy et al. [97] were able to show that pre-treatment serum IL-6 levels predicted survival and recurrence in HNSCC patients. Still, changes in cytokine levels in serum may have input on the regulatory effects of MO when stimulated under in vitro and autologous conditions. We observed no difference between autologous and serum-free culture conditions in terms of the predictive role of MO-derived IL-6 secretion.

It seems that increased MO responsiveness, as measured by IL-6 secretion, is a negative prognostic factor both with LPS and in co-culture with F-spheroids.

MOs in HNSCC patients might be functionally changed due to several factors related to presence of malignant disease. Cytokines and growth factors, produced in or around the vicinity of the tumour, could not only affect the immune system locally but also generally, i.e. by affecting monoblast development in the bone marrow. Such an MO-priming effect seems to be more qualitative than quantitative, i.e. non-linear to the tumour burden [96]. These findings strongly indicate that MOs in HNSCC patients are functionally changed as a consequence of disease and the influence of other factors, such as level of tumour burden and inflammation, are secondary to this effect. We actually found that IL- 6 production from MOs in co-culture with benign fragment spheroids has prognostic value as to locoregional recurrence and survival. Our hypothesis is that this might be a display of field cancerization whereby changed dysplastic epithelia is found throughout mucosa of both the upper and lower respiratory tracts, as well as to some extent in the oesophagus, which in turn may give rise to cancer at 
Table 1 Possible strategies feasible as to immunotherapy in head and neck squamous cell carcinoma

\begin{tabular}{llll}
\hline Strategy & Method & Goal & References \\
\hline Cancer vaccine based & Tumour associated antigens & Enhancement of tumour surveillance & [102, 103] \\
& Dendritic cells & Arrest of tumour development & and growth \\
Natural killer cells & Inhibiting neo-angiogenesis & [68] \\
$\begin{array}{l}\text { Modulation of function } \\
\text { of tumour associated } \\
\text { macrophages }\end{array}$ & Inhibiting type II differentiation of TAM & TAM as a vehicle for chemotherapeutical substances & Intra-tumoural therapy \\
& in hypoxic areas in tumour tissue & Monoclonal antibodies against \\
& Inhibition of TAM cytokine secretion & circulating IL-6 and IL-6R & [64] \\
STAT3 activation & Steroids, PS-341, Ecosapentaenoic acid, Atiprimod & Inhibition STAT3 activation & [105] \\
\hline
\end{tabular}

multiple sites [98]. An elevated production of IL-6 from BF-spheroids could be linked with dysplastic-transformed epithelia, which stimulates MOs, as shown by an elevated BF-spheroid co-culture response in patients who perished (from cancer disease) during follow-up. Alternatively, it may be a characteristic of MOs that is associated with prognosis under BF-co-culture condition. Such an explanation is in line with published studies both as to serum values of pro-inflammatory cytokines [99] and secretion of proinflammatory cytokines by immune cells [100].

\section{Inflammation and cytokine production}

It cannot be determined whether this observation is related to the effect of IL-6 per se or the increased IL-6 MO responsiveness, as a result of increased inflammatory response in diseased patients. A changed inflammatory state may be present in HNSCC patients, as shown by, e.g. increased ESR and lowered albumin values in serum [101]. Still, a pro-inflammatory cytokine, such as IL-6, could possibly enhance the inflammatory response towards the tumour in a way that could enhance tumour aggressiveness. IL- 6 may activate NF-kB, a nuclear regulator in the expression of multiple genes in cells, thereby making a possible link between infection, inflammation and carcinogens to cancer development [40]. The observed significantly higher production of IL- 6 by MOs in patients with recurrence and/or death from disease [96] might also be linked to an IL-6/glycoprotein130 stimulation, which activates STAT3 in an EGFR-independent manner [79]. STAT3 activation is associated with cell proliferation and prevention of apoptosis, thereby participating in oncogenesis [80] and has been shown to be up-regulated in HNSCC tissue and in the benign mucosa of the same patient [81].

\section{Future perspectives}

Several strategies might be feasible as to immunotherapy, e.g., cancer vaccine-based immunotherapy should enhance immunosurveillance and prevent and protect against growing tumours [102]. Trials have been done with tumourassociated antigens (TAA) and peptides though objective clinical responses are still rare [103]. Studies have been performed where MNPs have been used as an adjuvant tool in treatment of HNSCC [104, 105]. Many of these studies are Phase I and II studies particularly using DCs as an adjuvant to surgery, radiotherapy and chemotherapy [105]. Other clinical studies have also focused on the use of NK cells as a form of immunotherapy where endogenous NK cells are activated by infusions of cytokines, or allogeneic cells are adoptively transferred to a donor with cancer [106]. Unfortunately though, no reports have yet been published validating the use of this kind of immunotherapies as adjuvant therapy.

TAM in tumours might promote a type II stage induced in part by tumour hypoxia. In this way, TAM promotes tumour growth by inducing neo-angiogenesis. In this view, strategies could be developed to prevent TAMs from differentiating into a type 2 phenotype, thereby inhibiting neoangiogenesis. On the other hand, TAMs might be used as a vehicle for delivering anti-tumour "substances" to specific areas prone to hypoxia where agents, such as chemotherapeutical drugs, are less potent due to lack of blood vessels. One might also inhibit the function of TAMs themselves, e.g. cytokine secretion. IL- 6 might be one of the cytokines that might be targeted in the treatment of cancer in general. Monoclonal recombinant antibodies against circulating IL6 and the IL-6 receptor (IL-6R) have been successfully applied in the treatment of juvenile rheumatoid arthritis and Castleman disease [107]. Other strategies might be directed towards the IL-6/gp130 autocrine/paracrine mechanism that activates STAT3. Several substances are known to inhibit IL-6-induced activation of STAT3 [107], most notably steroids which are potent inhibitors of IL-6 production.

As interactions between MNPs and HNSCC are not completely disclosed, one might ponder on how the enhanced IL-6 production of MOs in HNSCC patients can be used in a clinical setting. Many cells produce IL- 6 and as such it is important to determine the nature of the main 
stimulus responsible for this raised IL-6 production by MNPs. This is an interesting and important line of exploration for future studies (Table 1).

Conflict of interest statement The authors declare that they have no conflict of interest.

Open Access This article is distributed under the terms of the Creative Commons Attribution Noncommercial License which permits any noncommercial use, distribution, and reproduction in any medium, provided the original author(s) and source are credited.

\section{References}

1. Jemal A, Siegel R, Ward E et al (2006) Cancer statistics. CA Cancer J Clin 56(2):106-130

2. Marur S, Forastiere AA (2008) Head and neck cancer: changing epidemiology, diagnosis, and treatment. Mayo Clin Proc 83(4):489-501

3. Wei WI (2002) Commentary: head and neck carcinomas in the developing world. BMJ 325(7368):827

4. Johnson N (2001) Tobacco use and oral cancer: a global perspective. J Dent Educ 65(4):328-339

5. McMahon S, Chen AY (2003) Head and neck cancer. Cancer Metastasis Rev 22(1):21-24

6. Forastiere A, Koch W, Trotti A, Sidransky D (2001) Head and neck cancer. N Engl J Med 345(26):1890-1900

7. Brockstein B, Haraf DJ, Rademaker AW et al (2004) Patterns of failure, prognostic factors and survival in locoregionally advanced head and neck cancer treated with concomitant chemoradiotherapy: a 9-year, 337-patient, multi-institutional experience. Ann Oncol 15(8):1179-1186

8. Pignon JP, Bourhis J, Domenge C, Designe L (2000) Chemotherapy added to locoregional treatment for head and neck squamouscell carcinoma: three meta-analyses of updated individual data. $\mathrm{MACH}-\mathrm{NC}$ Collaborative Group. Meta-analysis of chemotherapy on head and neck cancer. Lancet 355(9208):949-955

9. Cooper JS, Pajak TF, Forastiere AA et al (2004) Postoperative concurrent radiotherapy and chemotherapy for high-risk squamous-cell carcinoma of the head and neck. N Engl J Med 350(19): 1937-1944

10. Kim ES, Kies M, Herbst RS (2002) Novel therapeutics for head and neck cancer. Curr Opin Oncol 14(3):334-342

11. Seiwert TY, Cohen EE (2005) State-of-the-art management of locally advanced head and neck cancer. Br J Cancer 92(8):13411348

12. Bonner JA, Harari PM, Giralt J et al (2006) Radiotherapy plus cetuximab for squamous-cell carcinoma of the head and neck. $\mathrm{N}$ Engl J Med 354(6):567-578

13. Choong NW, Cohen EE (2006) Epidermal growth factor receptor directed therapy in head and neck cancer. Crit Rev Oncol Hematol 57(1):25-43

14. de Visser KE, Korets LV, Coussens LM (2005) De novo carcinogenesis promoted by chronic inflammation is B lymphocyte dependent. Cancer Cell 7(5):411-423

15. Van Ginderachter JA, Movahedi K, Hassanzadeh Ghassabeh G et al (2006) Classical and alternative activation of mononuclear phagocytes: picking the best of both worlds for tumor promotion. Immunobiology 211(6-8):487-501

16. Okamoto M, Ohe G, Oshikawa T et al (2000) Induction of Th1type cytokines by lipoteichoic acid-related preparation isolated from OK-432, a penicillin-killed streptococcal agent. Immunopharmacology 49(3):363-376
17. Baran J, Baj-Krzyworzeka M, Weglarczyk K, Ruggiero I, Zembala M (2004) Modulation of monocyte-tumour cell interactions by Mycobacterium vaccae. Cancer Immunol Immunother 53(12):1127-1134

18. Ooi VE, Liu F (2000) Immunomodulation and anti-cancer activity of polysaccharide-protein complexes. Curr Med Chem 7(7):715-729

19. Moschos SJ, Edington HD, Land SR et al (2006) Neoadjuvant treatment of regional stage IIIB melanoma with high-dose interferon alfa- $2 b$ induces objective tumor regression in association with modulation of tumor infiltrating host cellular immune responses. J Clin Oncol 24(19):3164-3171

20. Knecht R, Peters S, Solbach C, Baghi M, Gstottner W, Hambek M (2003) EGFR antibody-supplemented TPE-chemotherapy. Preclinical investigations to a novel approach for head and neck cancer induction treatment. Anticancer Res 23(6C):4789-4795

21. Tanaka S, Tatsuguchi A, Futagami S et al (2006) Monocyte chemoattractant protein 1 and macrophage cyclooxygenase 2 expression in colonic adenoma. Gut 55(1):54-61

22. Oba K, Teramukai S, Kobayashi M, Matsui T, Kodera Y, Sakamoto J (2007) Efficacy of adjuvant immunochemotherapy with polysaccharide $\mathrm{K}$ for patients with curative resections of gastric cancer. Cancer Immunol Immunother 56(6):905-911

23. Kumazawa H, Yamashita T, Tachikawa T, Minamino M, Nakata Y (1994) Local injection of OK-432/fibrinogen gel into head and neck carcinomas. Eur J Cancer 30A(12):1741-1744

24. Naito K, Ueda Y, Itoh T et al (2006) Mature dendritic cells generated from patient-derived peripheral blood monocytes in one-step culture using streptococcal preparation OK-432 exert an enhanced antigen-presenting capacity. Int J Oncol 28(6):1481-1489

25. Elojeimy S, McKillop JC, El-Zawahry AM et al (2006) FasL gene therapy: a new therapeutic modality for head and neck cancer. Cancer Gene Ther 13(8):739-745

26. Burnet FM (1970) The concept of immunological surveillance. Prog Exp Tumor Res 13:1-27

27. De Boer RJ, Hogeweg P (1985) Tumor escape from immune elimination: simplified precursor bound cytotoxicity models. J Theor Biol 113(4):719-736

28. Kerrebijn JD, Balm AJ, Freeman JL, Dosch HM, Drexhage HA (1999) Who is in control of the immune system in head and neck cancer? Crit Rev Oncol Hematol 31(1):31-53

29. Hellstrom I, Hellstrom KE (1983) Cell-mediated reactivity to human tumor-type associated antigens: does it exist? J Biol Response Mod 2(4):310-320

30. Pollard JW (2004) Tumour-educated macrophages promote tumour progression and metastasis. Nat Rev Cancer 4(1):71-78

31. Gorelik E, Gunji Y, Goldfarb RH (1988) Interaction of tumor cells and immune system in the metastatic process. Biochem Cell Biol 66(6):617-625

32. Miller FR (1993) Immune mechanisms in the sequential steps of metastasis. Crit Rev Oncog 4(3):293-311

33. Malmberg KJ, Ljunggren HG (2006) Escape from immune- and nonimmune-mediated tumor surveillance. Semin Cancer Biol 16(1):16-31

34. Lamagna C, Aurrand-Lions M, Imhof BA (2006) Dual role of macrophages in tumor growth and angiogenesis. J Leukoc Biol 80(4):705-713

35. Rakoff-Nahoum S (2006) Why cancer and inflammation? Yale J Biol Med 79(3-4):123-130

36. Bunt SK, Yang L, Sinha P, Clements VK, Leips J, Ostrand-Rosenberg $S$ (2007) Reduced inflammation in the tumor microenvironment delays the accumulation of myeloid-derived suppressor cells and limits tumor progression. Cancer Res 67(20):10019-10026

37. Hafkamp HC, Manni JJ, Speel EJ (2004) Role of human papillomavirus in the development of head and neck squamous cell carcinomas. Acta Otolaryngol 124(4):520-526 
38. Bunt SK, Sinha P, Clements VK, Leips J, Ostrand-Rosenberg S (2006) Inflammation induces myeloid-derived suppressor cells that facilitate tumor progression. J Immunol 176(1):284-290

39. Burstein E, Fearon ER (2008) Colitis and cancer: a tale of inflammatory cells and their cytokines. J Clin Invest 118(2):464-467

40. Hayden MS, West AP, Ghosh S (2006) NF-kappaB and the immune response. Oncogene 25(51):6758-6780

41. Allen CT, Ricker JL, Chen Z, Van Waes C (2007) Role of activated nuclear factor-kappaB in the pathogenesis and therapy of squamous cell carcinoma of the head and neck. Head Neck 29(10):959-971

42. Wang F, Arun P, Friedman J, Chen Z, Van Waes C (2009) Current and potential inflammation targeted therapies in head and neck cancer. Curr Opin Pharmacol 9(4):389-395

43. Heimdal JH, Aarstad HJ, Klementsen B, Olofsson J (1998) Disease stage related in vitro responsiveness of peripheral blood T-lymphocytes in patients with head and neck carcinoma. Acta Otolaryngol 118(6):887-891

44. Vlock DR (1991) Immunobiologic aspects of head and neck cancer. Clinical and laboratory correlates. Hematol Oncol Clin North Am 5(4):797-820

45. Chikamatsu K, Sakakura K, Whiteside TL, Furuya N (2007) Relationships between regulatory $\mathrm{T}$ cells and CD8+ effector populations in patients with squamous cell carcinoma of the head and neck. Head Neck 29(2):120-127

46. Aarstad HJ, Heimdal JH, Klementsen B, Olofsson J, Ulvestad E (2006) Presence of activated T lymphocytes in peripheral blood of head and neck squamous cell carcinoma patients predicts impaired prognosis. Acta Otolaryngol 126(12):1326-1333

47. Whiteside TL (2005) Immunobiology of head and neck cancer. Cancer Metastasis Rev 24(1):95-105

48. Johnston RB Jr (1988) Current concepts: immunology. Monocytes and macrophages. N Engl J Med 318(12):747-752

49. Seljelid R (1987) Effector functions of macrophages. Acta Med Scand Suppl 715:131-138

50. Seljelid R, Eskeland T (1993) The biology of macrophages: I. General principles and properties. Eur J Haematol 51(5):267-275

51. Fearon DT, Locksley RM (1996) The instructive role of innate immunity in the acquired immune response. Science 272(5258):50-53

52. Burke B, Lewis CE (2002) The macrophage. 2nd edn. Oxford University Press, New York

53. Vuk-Pavlovic S (2007) Rebuilding immunity in cancer patients. Blood Cells Mol Dis 40(1):94-100

54. Kusmartsev S, Gabrilovich DI (2006) Role of immature myeloid cells in mechanisms of immune evasion in cancer. Cancer Immunol Immunother 55(3):237-245

55. Gallo O, Gori AM, Attanasio M et al (1993) Interleukin-1 beta and interleukin- 6 release by peripheral blood monocytes in head and neck cancer. Br J Cancer 68(3):465-468

56. Heimdal JH, Aarstad HJ, Klementsen B, Olofsson J (1999) Ex vivo interleukin (IL)-1 beta, IL-6, IL-12 and tumor necrosis factor-alpha responsiveness with monocytes from patients with head and neck carcinoma. Eur Arch Otorhinolaryngol 256(5):250-256

57. Mytar B, Woloszyn M, Szatanek R et al (2003) Tumor cellinduced deactivation of human monocytes. J Leukoc Biol 74(6): 1094-1101

58. Chen Z, Malhotra PS, Thomas GR et al (1999) Expression of proinflammatory and proangiogenic cytokines in patients with head and neck cancer. Clin Cancer Res 5(6):1369-1379

59. Watkins SK, Egilmez NK, Suttles J, Stout RD (2007) IL-12 rapidly alters the functional profile of tumor-associated and tumorinfiltrating macrophages in vitro and in vivo. J Immunol 178(3):1357-1362
60. Valenti R, Huber V, Iero M, Filipazzi P, Parmiani G, Rivoltini L (2007) Tumor-released microvesicles as vehicles of immunosuppression. Cancer Res 67(7):2912-2915

61. Li C, Shintani S, Terakado N, Nakashiro K, Hamakawa H (2002) Infiltration of tumor-associated macrophages in human oral squamous cell carcinoma. Oncol Rep 9(6):1219-1223

62. Liss C, Fekete MJ, Hasina R, Lam CD, Lingen MW (2001) Paracrine angiogenic loop between head-and-neck squamous-cell carcinomas and macrophages. Int J Cancer 93(6):781-785

63. Johansson M, Tan T, de Visser KE, Coussens LM (2007) Immune cells as anti-cancer therapeutic targets and tools. J Cell Biochem 101(4):918-926

64. Kross KW, Heimdal JH, Olsnes C, Olofsson J, Aarstad HJ (2005) Head and neck squamous cell carcinoma spheroid- and monocyte spheroid-stimulated IL- 6 and monocyte chemotactic protein-1 secretion are related to TNM stage, inflammatory state and tumor macrophage density. Acta Otolaryngol 125(10):1097-1104

65. Ohta M, Kitadai Y, Tanaka S et al (2002) Monocyte chemoattractant protein-1 expression correlates with macrophage infiltration and tumor vascularity in human esophageal squamous cell carcinomas. Int J Cancer 102(3):220-224

66. Marcus B, Arenberg D, Lee J et al (2004) Prognostic factors in oral cavity and oropharyngeal squamous cell carcinoma. Cancer 101(12):2779-2787

67. Mantovani A, Allavena P, Sica A (2004) Tumour-associated macrophages as a prototypic type II polarised phagocyte population: role in tumour progression. Eur J Cancer 40(11):1660-1667

68. Ueno T, Toi M, Saji H et al (2000) Significance of macrophage chemoattractant protein-1 in macrophage recruitment, angiogenesis, and survival in human breast cancer. Clin Cancer Res 6(8):3282-3289

69. Nakayama Y, Nagashima N, Minagawa N et al (2002) Relationships between tumor-associated macrophages and clinicopathological factors in patients with colorectal cancer. Anticancer Res 22(6C):4291-4296

70. Kleine-Lowinski K, Gillitzer R, Kuhne-Heid R, Rosl F (1999) Monocyte-chemo-attractant-protein-1 (MCP-1)-gene expression in cervical intra-epithelial neoplasias and cervical carcinomas. Int J Cancer 82(1):6-11

71. Leek RD, Harris AL (2002) Tumor-associated macrophages in breast cancer. J Mammary Gland Biol Neoplasia 7(2):177-189

72. Valkovic T, Fuckar D, Stifter S et al (2005) Macrophage level is not affected by monocyte chemotactic protein-1 in invasive ductal breast carcinoma. J Cancer Res Clin Oncol 131(7):453-458

73. Varney ML, Johansson SL, Singh RK (2005) Tumour-associated macrophage infiltration, neovascularization and aggressiveness in malignant melanoma: role of monocyte chemotactic protein-1 and vascular endothelial growth factor-A. Melanoma Res 15(5):417-425

74. Sica A, Schioppa T, Mantovani A, Allavena P (2006) Tumourassociated macrophages are a distinct M2 polarised population promoting tumour progression: potential targets of anti-cancer therapy. Eur J Cancer 42(6):717-727

75. Stout RD, Suttles J (2004) Functional plasticity of macrophages: reversible adaptation to changing microenvironments. J Leukoc Biol 76(3):509-513

76. Kontny E, Ziolkowska M, Ryzewska A, Maslinski W (1999) Protein kinase c-dependent pathway is critical for the production of pro-inflammatory cytokines (TNF-alpha, IL-1beta, IL-6). Cytokine 11(11):839-848

77. Hodge DR, Hurt EM, Farrar WL (2005) The role of IL-6 and STAT3 in inflammation and cancer. Eur J Cancer 41(16):25022512

78. Kamimura D, Ishihara K, Hirano T (2003) IL-6 signal transduction and its physiological roles: the signal orchestration model. Rev Physiol Biochem Pharmacol 149:1-38 
79. Sriuranpong V, Park JI, Amornphimoltham P, Patel V, Nelkin BD, Gutkind JS (2003) Epidermal growth factor receptor-independent constitutive activation of STAT3 in head and neck squamous cell carcinoma is mediated by the autocrine/paracrine stimulation of the interleukin 6/gp130 cytokine system. Cancer Res 63(11):2948-2956

80. Bowman T, Garcia R, Turkson J, Jove R (2000) STATs in oncogenesis. Oncogene 19(21):2474-2488

81. Grandis JR, Drenning SD, Zeng Q et al (2000) Constitutive activation of Stat 3 signaling abrogates apoptosis in squamous cell carcinogenesis in vivo. Proc Natl Acad Sci USA 97(8):42274232

82. Kanazawa T, Nishino H, Hasegawa $M$ et al (2007) Interleukin-6 directly influences proliferation and invasion potential of head and neck cancer cells. Eur Arch Otorhinolaryngol 264(7):815821

83. Nishino H, Miyata M, Kitamura K (1998) The effect of interleukin-6 on enhancing the invasiveness of head and neck cancer cells in vitro. Eur Arch Otorhinolaryngol 255(9):468-472

84. Taub DD, Proost P, Murphy WJ et al (1995) Monocyte chemotactic protein-1 (MCP-1), -2, and -3 are chemotactic for human $\mathrm{T}$ lymphocytes. J Clin Invest 95(3):1370-1376

85. Allavena P, Bianchi G, Zhou D et al (1994) Induction of natural killer cell migration by monocyte chemotactic protein-1, -2 and 3. Eur J Immunol 24(12):3233-3236

86. Leonard EJ, Skeel A, Yoshimura T, Rankin J (1993) Secretion of monocyte chemoattractant protein-1 (MCP-1) by human mononuclear phagocytes. Adv Exp Med Biol 351:55-64

87. Yoshimura T, Robinson EA, Tanaka S, Appella E, Kuratsu J, Leonard EJ (1989) Purification and amino acid analysis of two human glioma-derived monocyte chemoattractants. J Exp Med 169(4):1449-1459

88. Conti I, Rollins BJ (2004) CCL2 (monocyte chemoattractant protein-1) and cancer. Semin Cancer Biol 14(3):149-154

89. Huang B, Lei Z, Zhao J et al (2007) CCL2/CCR2 pathway mediates recruitment of myeloid suppressor cells to cancers. Cancer Lett 252(1):86-92

90. Bailey C, Negus R, Morris A et al (2007) Chemokine expression is associated with the accumulation of tumour associated macrophages (TAMs) and progression in human colorectal cancer. Clin Exp Metastasis 24(2):121-130

91. Bemelmans MH, van Tits LJ, Buurman WA (1996) Tumor necrosis factor: function, release and clearance. Crit Rev Immunol 16(1):1-11

92. Bradley JR (2008) TNF-mediated inflammatory disease. J Pathol 214(2):149-160
93. Kumar R, Herbert PE, Warrens AN (2005) An introduction to death receptors in apoptosis. Int J Surg 3(4):268-277

94. Yao J, Mackman N, Edgington TS, Fan ST (1997) Lipopolysaccharide induction of the tumor necrosis factor-alpha promoter in human monocytic cells. Regulation by Egr-1, c-Jun, and NF-kappaB transcription factors. J Biol Chem 272(28):17795-17801

95. Heimdal JH, Kross K, Klementsen B, Olofsson J, Aarstad HJ (2008) Stimulated monocyte IL-6 secretion predicts survival of patients with head and neck squamous cell carcinoma. BMC Cancer 8:34

96. Kross KW, Heimdal JH, Olsnes C, Olofsson J, Aarstad HJ (2008) Co-culture of head and neck squamous cell carcinoma spheroids with autologous monocytes predicts prognosis. Scand J Immunol 67(4):392-399

97. Duffy SA, Taylor JM, Terrell JE et al (2008) Interleukin-6 predicts recurrence and survival among head and neck cancer patients. Cancer 113(4):750-757

98. Ha PK, Califano JA (2003) The molecular biology of mucosal field cancerization of the head and neck. Crit Rev Oral Biol Med 14(5):363-369

99. De Schutter H, Landuyt W, Verbeken E, Goethals L, Hermans R, Nuyts S (2005) The prognostic value of the hypoxia markers CA IX and GLUT 1 and the cytokines VEGF and IL 6 in head and neck squamous cell carcinoma treated by radiotherapy \pm chemotherapy. BMC Cancer 5(1):42

100. Pries R, Wollenberg B (2006) Cytokines in head and neck cancer. Cytokine Growth Factor Rev 17(3):141-146

101. Riedel F, Zaiss I, Herzog D, Gotte K, Naim R, Hormann K (2005) Serum levels of interleukin- 6 in patients with primary head and neck squamous cell carcinoma. Anticancer Res 25(4):2761-2765

102. Rapidis AD, Wolf GT (2009) Immunotherapy of head and neck cancer: current and future considerations. J Oncol 2009:346345

103. Ward RC, Kaufman HL (2007) Targeting costimulatory pathways for tumor immunotherapy. Int Rev Immunol 26(3-4):161-196

104. Whiteside TL, Vujanovic NL, Herberman RB (1998) Natural killer cells and tumor therapy. Curr Top Microbiol Immunol 230:221-244

105. Leibowitz MS, Nayak JV, Ferris RL (2008) Head and neck cancer immunotherapy: clinical evaluation. Curr Oncol Rep 10(2):162-169

106. Ljunggren HG, Malmberg KJ (2007) Prospects for the use of NK cells in immunotherapy of human cancer. Nat Rev Immunol 7(5):329-339

107. Hong DS, Angelo LS, Kurzrock R (2007) Interleukin-6 and its receptor in cancer: implications for translational therapeutics. Cancer 110(9):1911-1928 